\title{
A Review of International Space Station Habitable Element Equipment Offgassing Characteristics
}

\author{
Jay L. Perry ${ }^{1}$ \\ NASA George C. Marshall Space Flight Center, MSFC, Alabama, 35812
}

\begin{abstract}
Crewed spacecraft trace contaminant control employs both passive and active methods to achieve acceptable cabin atmospheric quality. Passive methods include carefully selecting materials of construction, employing clean manufacturing practices, and minimizing systems and payload operational impacts to the cabin environment. Materials selection and manufacturing processes constitute the first level of equipment offgassing control. An elementlevel equipment offgassing test provides preflight verification that passive controls have been successful. Offgassing test results from multiple International Space Station (ISS) habitable elements and cargo vehicles are summarized and implications for active contamination control equipment design are discussed.
\end{abstract}

\section{Nomenclature}

$C_{i}=$ chemical compound cabin concentration

$g_{i} \quad=$ chemical compound generation rate

$m g \quad=$ milligram

$m^{3} \quad=$ cubic meter

$n=$ number of intervals between sampling events

$t \quad=$ time

$V \quad=$ spacecraft cabin free volume

\section{Introduction}

M

ANY factors contribute to the trace chemical contaminant load and, therefore, the cabin air quality on board crewed spacecraft. These include spacecraft cabin characteristics, crew size and activities, mission duration and objectives, materials selection, and vehicle manufacturing processes. Trace chemical contaminants produced from pervasive sources such as equipment offgassing and human metabolism present a challenge to maintaining acceptable cabin air quality.

Achieving acceptable cabin air quality must balance a large number of competing design elements. ${ }^{1-2}$ Both passive and active control techniques are used during a spacecraft's design, fabrication, and operational phases. Active contamination control methods involve providing equipment that purifies and revitalizes the cabin atmosphere during flight operations while passive methods are employed across the spacecraft's entire life cycle from conceptual design through flight operations. The offgassing test for the fully assembled spacecraft is a tool that has been used successfully during all crewed spacecraft programs to provide insight into how effectively the passive contamination control methods limit the equipment offgassing component of the overall contaminant generation load.

\section{The Role of Spacecraft Offgassing Tests for Ensuring Cabin Air Quality}

Conducting offgassing tests on crewed spacecraft helps to verify that the various contamination control methods for minimizing the trace chemical offgassing load during the design and manufacturing have been successful. The offgassing test is an important tool for collecting the data necessary for this verification and fits within an operational framework to continually ensure that the cabin atmosphere is maintained within acceptable standards. The framework involves three primary elements - collecting data during pre-launch spacecraft offgassing tests, employing predictive techniques to evaluate cabin atmospheric quality at key mission stages, and monitoring cabin atmospheric

\footnotetext{
${ }^{1}$ Senior Engineer, Environmental Control Systems, Engineering Directorate, Space Systems Department, ECLS System Development Branch, NASA MSFC/ES62, MSFC, Alabama, 35812.
} 
quality via various techniques. Monitoring techniques may employ archival sampling with ground-based analysis and in-flight sampling and analysis methods.

The first element, conducting a pre-flight spacecraft offgassing test, is used primarily for new spacecraft and habitable modules. During the International Space Station (ISS) program, offgassing tests ranging in duration from six to more than fifteen days have been conducted for eight ISS U.S. on-orbit segment (USOS) cabin modules and four cargo vehicles. As well, data have been reported to the National Aeronautics and Space Administration (NASA) by the Institute for Medico-Biological Problems (IMBP) via RSC Energia for three Russian on-orbit segment (ROS) cabin modules. Ideally, the offgassing test duration is at least one-fifth the elapsed time interval between the module's final pre-launch closeout and purge on the ground and first entry during flight. Samples are ideally collected at the beginning, middle, and end of the test. The data collected from these tests are analyzed to determine offgassing rates. Combined with human metabolic loads, the offgassing rates derived from these tests are assessed against the active trace contaminant control capabilities on board the ISS to ensure that the load does not exceed the active contamination control capabilities.

The second element uses offgassing rate data to predict transient cabin atmospheric quality changes during quiescent periods and the impacts presented by adding new habitable volumes and equipment to an existing spacecraft such as the ISS. Both vehicle offgassing test data and a generalized equipment offgassing rate model may serve as the basis for predictive assessments. The generalized equipment offgassing rate model served as the basis for the ISS trace contaminant control subassembly (TCCS) design and is based upon a statistical treatment of numerous individual equipment offgassing tests conducted during the Spacelab program. ${ }^{3}$ Comparison of this load model to results obtained from ISS element offgassing tests indicates that this model is representative and conservative of the general offgassing characteristics of U.S. hardware. ${ }^{4}$ For a cargo transfer mission, the net cargo mass transferred to the spacecraft is considered to provide the most realistic estimate of the net growth in the total spacecraft equipment offgassing load. The total predicted trace contaminant generation rate at any particular time is the sum of the offgassing rate derived from pre-flight testing, the human metabolic rate, and the predicted rate for net cargo transferred.

The third element involves monitoring the trace chemical contaminant concentration in the cabin atmosphere by various methods. Methods may be archival or near real-time. ${ }^{5}$ Monitoring results are assessed to evaluate trends. This provides a direct, continuing verification of not only are the active contamination control methods but also for the passive methods employed during engineering design and spacecraft assembly and ground processing.

\section{ISS Element Offgassing Test Summary}

During ISS on-orbit assembly beginning in 1998 and continuing through 2010, testing has been conducted to characterize the offgassing rates from cargo elements and vehicles, USOS habitable elements, and ROS habitable elements. Trace contaminant concentration, $C_{i}$, changes over time, $t$, as denoted by equation 1 . Generation rate, $g_{i}$, is typically assumed to be constant over time. This assumption has been determined to be reasonably accurate for most element offgassing predictions. The module free volume, $V$, is constant and accounts for the volume occupied by internal equipment.

$$
\frac{d C_{i}}{d t}=\frac{g_{i}}{V}
$$

Trace contaminant generation rates are derived from the analytical results of offgassing test samples collected from a sealed module or vehicle. Sample sets are collected at hatch closure, an intermediate time during the test, and at the end of the test. The first sample set serves as the starting basis at time zero. Individual contaminant generation rates are derived using equation 2 which is equation 1 in differential form solved for the generation rate.

$$
g_{i}=V \sum_{i=l}^{n} \frac{1}{n}\left\{\frac{C_{i+l}-C_{i}}{t_{i+1}-t_{i}}\right\}
$$

In equation $2, g_{i}$ is the individual contaminant generation rate in $\mathrm{mg} / \mathrm{h}, V$ is the cabin free volume in $\mathrm{m}^{3}, n$ is the number of intervals between sampling events during the test, $C_{i}$ is the average concentration at the beginning of a time increment, $t_{i}$, during the offgassing test in $\mathrm{mg} / \mathrm{m}^{3}$, and $C_{i+1}$ is the average concentration at the end of a time increment, $t_{i+1}$, during the test.

Results from each element offgassing test have been evaluated to determine time-averaged rates according to equation 2. The following discussion provides a summary of the derived offgassing rates and selected testing parameters such as duration, module free volume, number of sampling events, and the percentage of the internal equipment installed. 


\section{A. Cargo Elements and Vehicles}

Offgassing tests of two cargo elements and two cargo vehicles have been conducted. Table 1 summarizes the total non-methane chemical offgassing rates derived from tests conducted on the first two multi-purpose logistics module (MPLM) cargo elements, the first Automated Transfer Vehicle (ATV-1), and the first H-II Transfer Vehicle (HTV-1) as well as some characteristics for each module. The cargo element and cargo vehicle total offgassing rates range from $22.5 \mathrm{mg} /$ day to $39.8 \mathrm{mg} /$ day. The average is $34.2 \mathrm{mg} /$ day. Normalizing the rate over free volume shows reasonable consistency, averaging $0.814 \mathrm{mg} / \mathrm{day}-\mathrm{m}^{3}$.

\begin{tabular}{|c|c|c|c|c|c|c|}
\hline ELEMENT & $\begin{array}{l}\text { TOTAL } \\
\text { RATE } \\
\text { (mg/day) }\end{array}$ & $\begin{array}{c}\text { TEST } \\
\text { LENGTH } \\
\text { (hours) }\end{array}$ & $\begin{array}{l}\text { SAMPLE } \\
\text { EVENTS }^{\text {a }}\end{array}$ & $\begin{array}{c}\text { INTERNAL } \\
\text { MASS } \\
(\%)\end{array}$ & $\begin{array}{c}\text { FREE } \\
\text { VOLUME }^{\text {OLLUM }} \\
\left(\mathbf{m}^{\mathbf{3}}\right)\end{array}$ & $\begin{array}{c}\text { SPECIFIC } \\
\text { RATE } \\
\left.(\mathrm{mg} / \text { day-m })^{3}\right)\end{array}$ \\
\hline MPLM FM-1 & 39.4 & 209.8 & 3 & 78.76 & 45.02 & 0.875 \\
\hline MPLM FM-2 & 34.99 & 233 & 3 & 70.54 & 45.02 & 0.777 \\
\hline ATV-1 & 39.76 & 205.7 & 11 & 100 & 41 & 0.97 \\
\hline HTV-1 & 22.5 & 366.4 & 2 & 98.3 & 35.46 & 0.634 \\
\hline
\end{tabular}

a. Includes sample at time zero.

b. SSP 50623, Joint Environmental Control and Life Support Functional Strategy Document, Table 4.2-1.

\section{Table 1. Cargo element offgassing summary.}

While all three of the MPLM flight modules (FM) were subjected to 48-hour offgassing tests before shipment to the launch site, the tests did not include the cargo. ${ }^{6-7}$ The pre-shipment offgassing tests showed the MPLM FM-1 rate to be quite high at $293 \mathrm{mg} /$ day with methylbenzene, naphthalene, and methylpentane the most significant contributors. MPLM FM-2 pre-shipment testing also indicated a very high 799 mg/day offgassing rate. Benzene, $\mathrm{n}$ butanol, and styrene were major contributors to the result. These high rates can be indicative of new equipment and coatings. Offgassing rates have been observed to decay over time. A 45-day study of the offgassing rates of 20 typical spacecraft materials of construction showed approximately $86 \%$ decrease in rate. ${ }^{8}$ This equates to approximately $1.9 \%$ rate decay per day. A final offgassing evaluation that included the FM and its cargo indicates an average $90 \%$ reduction of the rate observed before FM shipment to the launch site. This experience is instructive because it supports conducting offgassing tests as close to the launch date as possible to ensure the most reliable result for predicting the in-flight equipment offgassing characteristics.

No offgassing tests were conducted for the re-flight of FM-1 and FM-2 because the results from the first two MPLM missions showed no significant difference in offgassing load for the two FMs that contained different cargo. These first tests, by demonstrating uniformity for different FMs containing different cargo, validated the cargo vehicle's material selection and control processes as well as ground processing practices for limiting chemical contamination. Therefore, subsequent MPLM trace contaminant control effectiveness has been evaluated using predictive techniques combined with collecting in-flight first entry samples.

Each new cargo element, however, is subjected to offgassing testing. Offgassing tests were completed on the first Automated Transfer Vehicle (ATV) developed by the European Space Agency (ESA) and the first H-II Transfer Vehicle (HTV) developed by the Japanese Aerospace Exploration Agency (JAXA). The ATV-1 testing and flight occurred in 2008 and the HTV-1 testing and flight occurred in 2009. The second ATV and HTV missions are scheduled for 2010. Vehicle offgassing tests are planned for the second missions. The need for offgassing tests of the ATV and HTV beyond their second missions will be evaluated based on the test results consistency between the first two missions. Because the ATV and HTV are disposable and new vehicles are built for each mission, it may be prudent to retain an offgassing test of the empty vehicle to ensure manufacturing process consistency.

\section{B. U.S. On-orbit Segment Elements}

Eight major habitable elements of the USOS have completed offgassing tests. The total offgassing rates, summarized by Table 2, show more variability than the cargo vehicles. Large elements, such as the U.S. laboratory (USL) and Japanese pressurized experiment module (JEM PM) have the highest offgassing rates. The specific rate for the Japanese pressurized logistics module (JEM ELM PS) is very similar to those for Node 2 and Node 3 . The European Space Agency's attached pressurized module (APM), also known as Columbus, has a very low offgassing rate compared to modules of similar size. Specific rates normalized to free volume range from $0.074 \mathrm{mg} / \mathrm{day}-\mathrm{m}^{3}$ to 1.359 $\mathrm{mg} /$ day $-\mathrm{m}^{3}$. The average specific rate for USOS elements is $0.652 \mathrm{mg} /$ day $-\mathrm{m}^{3}$. This is approximately $20 \%$ lower than the cargo element specific rate. 


\begin{tabular}{|c|c|c|c|c|c|c|}
\hline ELEMENT & $\begin{array}{c}\text { TOTAL } \\
\text { RATE } \\
\text { (mg/day) }\end{array}$ & $\begin{array}{c}\text { TEST } \\
\text { LENGTH } \\
\text { (hours) }\end{array}$ & $\begin{array}{l}\text { SAMPLE } \\
\text { EVENTS }^{\text {a }}\end{array}$ & $\begin{array}{c}\text { INTERNAL } \\
\text { MASS } \\
(\%)\end{array}$ & $\begin{array}{c}\text { FREE } \\
\text { VOLUME }^{b} \\
\left(\mathbf{m}^{3}\right)\end{array}$ & $\begin{array}{c}\text { SPECIFIC } \\
\text { RATE } \\
\left.(\mathbf{m g} / \text { day-m })^{3}\right)\end{array}$ \\
\hline APM & 4.76 & 456 & 3 & 100 & 64.25 & 0.074 \\
\hline JEM ELM PS & 6.73 & 551.9 & 3 & 77 & 39.04 & 0.172 \\
\hline JEM PM & 169.6 & 288.9 & 3 & 93.4 & 124.79 & 1.359 \\
\hline Node 1 & 60.96 & 118.6 & 3 & 93.4 & 55.16 & 1.105 \\
\hline Node 2 & 7.92 & 567.1 & 4 & 100 & 62 & 0.128 \\
\hline Node 3 & 10.75 & 790.1 & 3 & 100 & 62.02 & 0.173 \\
\hline USL & 121.9 & 443.7 & 3 & 80 & 97.69 & 1.248 \\
\hline Airlock & 28.71 & 354 & 3 & 75 & 30.05 & 0.955 \\
\hline
\end{tabular}

Table 2. USOS element offgassing summary.

\section{Russian On-orbit Segment Elements}

Offgassing test results have been reported from ROS elements. Wide total rate variation is noted as shown in Table 3. Significant offgassing from the alcohol, ester, and ketone functional classes drive the service module (SM) offgassing rate. Of particular note is that ethyl acetate accounts for $45 \%$ of the total SM offgassing rate. Offgassing from the functional cargo block (FGB) and mini research module-2 (MRM-2) elements are more consistent with the cargo elements and USOS elements. The average specific offgassing rate normalized to free volume is 1.675 $\mathrm{mg} / \mathrm{day}-\mathrm{m}^{3}$. This is more than twice the total offgassing rate observed for cargo elements and USOS elements.

\begin{tabular}{|c|c|c|c|c|c|c|}
\hline ELEMENT & $\begin{array}{c}\text { TOTAL } \\
\text { RATE } \\
\text { (mg/day) }\end{array}$ & $\begin{array}{c}\text { TEST } \\
\text { LENGTH } \\
\text { (hours) }\end{array}$ & $\begin{array}{l}\text { SAMPLE } \\
\text { EVENTS }^{\text {a }}\end{array}$ & $\begin{array}{c}\text { INTERNAL } \\
\text { MASS } \\
(\%)\end{array}$ & $\begin{array}{c}\text { FREE } \\
\text { VOLUME }^{b} \\
\left(\mathbf{m}^{3}\right)\end{array}$ & $\begin{array}{c}\text { SPECIFIC } \\
\text { RATE } \\
\left(\text { mg/day-m }^{3}\right)\end{array}$ \\
\hline FGB & 35.76 & 48 & 3 & 100 & 54.5 & 0.656 \\
\hline SM & 233 & 48 & 5 & 100 & 77 & 3.026 \\
\hline MRM-2 & 16.8 & 134 & 6 & 100 & 12.5 & 1.344 \\
\hline
\end{tabular}

a. Includes sample at time zero.

b. SSP 50623, Joint Environmental Control and Life Support Functional Strategy Document, Table 4.2-2.

Table 3. ROS element offgassing summary.

\section{Chemical Class Contributions to ISS Element Offgassing Rates}

Many individual chemical compounds contribute to the total offgassing rate. For this reason it is helpful to group individual compounds according to functional classes. Compounds in the alcohol, aldehyde, aromatic, ester, ether, halocarbon, aliphatic and paraffinic hydrocarbon, ketone, and organosilicone classes are typically observed. Carbon monoxide is sometimes found as well as other compounds such as carbon disulfide. The contribution to total offgassing rate by compounds in functional classes is discussed.

\section{A. Cargo Elements and Vehicles}

Compounds from the alcohol, halocarbon, ketone, and organosilicaone classes contribute significantly to cargo element total offgassing rates according to the summary in Table 4 . Carbon monoxide occasionally is found in significant quantities as it was during the HTV-1 test. Due to this result, extra precautions were implemented during on-orbit first entry operations. Fortunately carbon monoxide monitoring during first entry operations indicated a signifi-

\begin{tabular}{|c|c|c|c|c|}
\hline \multirow{2}{*}{$\begin{array}{l}\text { CHEMICAL } \\
\text { CLASS }\end{array}$} & \multicolumn{4}{|c|}{ OFFGASSING RATE (mg/hour) } \\
\hline & $\begin{array}{c}\text { MPLM } \\
\text { FM-1 }\end{array}$ & $\begin{array}{c}\text { MPLM } \\
\text { FM-2 }\end{array}$ & ATV-1 & HTV-1 \\
\hline Alcohols & 0.475 & 0.357 & 0.063 & 0.273 \\
\hline Aldehydes & 0.033 & 0.061 & 0.063 & 0 \\
\hline Aromatics & 0.002 & 0.078 & 0.091 & 0.007 \\
\hline Esters & 0 & 0 & 0.068 & 0 \\
\hline Ethers & 0 & 0 & 0.011 & 0 \\
\hline Halocarbons & 0.576 & 0.04 & 0.02 & 0 \\
\hline Hydrocarbons & 0 & 0 & 0.052 & 0.223 \\
\hline Ketones & 0.275 & 0.244 & 0.402 & 0.108 \\
\hline Organosilicones & 0.218 & 0.677 & 0.141 & 0.253 \\
\hline Carbon monoxide & 0 & 0 & 0.108 & 5.167 \\
\hline Other & 0.006 & 0 & 0.001 & 0.074 \\
\hline TOTAL & 1.585 & 1.457 & 1.020 & 6.105 \\
\hline
\end{tabular}

Table 4. Functional class contribution to cargo element and cargo vehicle offgassing. 
cantly lower generation rate than the offgassing test predicted. Carbon monoxide was also observed in offgassing test samples collected from the ATV-1 but to a lesser extent. Other areas of note include the significant halocarbon contribution to the total offgassing rate for the MPLM FM-1 and the organosilicone contribution for the MPLM FM-1 compared to other cargo elements and vehicles. Both MPLM offgassing test results also reported offgassing from the ketone class.

Fig. 1 shows the composition of the average 1.25 $\mathrm{mg} /$ hour total offgassing rate for the four cargo element and vehicle tests. This result uses a carbon monoxide generation rate indicative of the HTV-1 first entry condition rather than the raw offgassing test result. On average the greatest contributors include the alcohol, halocarbon, ketone, and organosilicone functional classes. Ethanol, 2-propanol, and nbutanol are commonly reported in the alcohol functional class. The ketone functional class typically has 2-propanone, 2-butanone, and cyclohexanone as major contributors. Trimethylsilanol, hexamethyltrisiloxane, octamethylcyclotetrasiloxane, and decamethylcyclopentasiloxane are typically observed in offgassing test samples.

\section{B. U.S. On-orbit Segment Elements}

Like the cargo elements and vehicles, the alcohol, halocarbon, ketone, and organosilicone classes contribute most significantly to the total offgassing rate. Table 5 shows the offgassing rate for the alcohol functional class is greatest for the JEM PM, Node 1, Node 2, Node 3, USL, and airlock elements. A very high $6.417 \mathrm{mg} / \mathrm{hour} 2$ propanol generation rate accounts for $>99 \%$ of the alcohol load observed during the JEM PM test. Halocarbon loading was found to be most significant for Node 1 and the USL. Dichloromethane accounted for $46 \%$ and $53 \%$ of the halocarbon rate for the USL and Node 1, respectively. The remainder of the Node 1 halocarbon rate is attributed to 1,1,2-trichloro-1,2,2-trifluoroethane (Freon 113). The appearance of Freon 113 is rare because it is the subject of controls relating to atmospheric ozone depletion. The Node 1 test is the only one that reports the presence of Freon 113. Carbon monoxide was observed only during testing of the Node 2, Node 3, and USL elements. Organosilicone compounds were commonly observed in offgassing test samples obtained from all USOS elements.

\begin{tabular}{|l|r|r|r|r|r|r|r|r|}
\hline \multirow{2}{*}{$\begin{array}{c}\text { CHEMICAL } \\
\text { CLASS }\end{array}$} & \multicolumn{7}{|c|}{ OFFGASSING RATE (mg/hour) } \\
\cline { 2 - 9 } & APM & $\begin{array}{c}\text { JEM } \\
\text { ELM PS }\end{array}$ & $\begin{array}{c}\text { JEM } \\
\text { PM }\end{array}$ & Node 1 & Node 2 & Node 3 & \multicolumn{1}{c|}{ USL } & Airlock \\
\hline Alcohols & 0.042 & 0.01 & 6.458 & 1.9 & 0.112 & 0.214 & 2.75 & 0.68 \\
\hline Aldehydes & 0.007 & 0.018 & 0.01 & 0.017 & 0.022 & 0.007 & 0.0124 & 0.02 \\
\hline Aromatics & 0.009 & 0.004 & 0 & 0.092 & 0.006 & 0.011 & 0.0618 & 0.02 \\
\hline Esters & 0 & 0 & 0 & 0 & 0 & 0.002 & 0 & 0 \\
\hline Ethers & 0 & 0 & 0 & 0 & 0 & 0 & 0 & 0 \\
\hline Halocarbons & 0 & 0.002 & 0 & 0.157 & 0.014 & 0.019 & 0.0887 & 0.01 \\
\hline Hydrocarbons & 0 & 0.002 & 0 & 0 & 0 & 0 & 0 & 0 \\
\hline Ketones & 0.036 & 0.008 & 0.033 & 0.258 & 0.047 & 0.039 & 0.622 & 0.08 \\
\hline Organosilicones & 0.104 & 0.123 & 0.55 & 0.119 & 0.084 & 0.056 & 0.828 & 0.383 \\
\hline Carbon monoxide & 0 & 0 & 0 & 0 & 0.035 & 0.07 & 0.545 & 0 \\
\hline Other & 0 & 0 & 0 & 0 & 0.009 & 0.03 & 0 & 0 \\
\hline TOTAL & $\mathbf{0 . 1 9 8}$ & $\mathbf{0 . 1 6 7}$ & $\mathbf{7 . 0 5 1}$ & $\mathbf{2 . 5 4 3}$ & $\mathbf{0 . 3 2 9}$ & $\mathbf{0 . 4 4 8}$ & $\mathbf{4 . 9 0 8}$ & $\mathbf{1 . 1 9 3}$ \\
\hline
\end{tabular}

Table 5. Functional class contribution to USOS element offgassing. 
Fig. 2 shows the functional group contribution to the average $2.105 \mathrm{mg} /$ hour USOS element offgassing rate. The high 2-propanol rate observed during the JEM PM testing is treated as an outlier and assigned a rate similar to other elements for the summary depicted by Fig. 2. Compared to the cargo elements, the $55.4 \%$ alcohol group contribution is more than two times higher while the halocarbon and ketone contributions, $7.1 \%$ and $10.8 \%$, respectively, are nearly two times lower. Ethanol, 2-propanol, and n-butanol predominate in the alcohol class. Two compounds in the ketone class, 2-propanone and 2-butanone, are reported in test results for all of the USOS elements. A third ketone, cyclohexanone, is reported in the test results for the Node 1, Node 2, Node 3, USL, and airlock elements. The contribution by organosilicone compounds to the average USOS element offgassing rate is slightly lower compared to that for the cargo elements. Trimethylsilanol is reported in all USOS element offgassing test results except for Node 1. Two other organosilicone compounds, hexamethylcyclotrisiloxane and octamethylcyclotrisiloxane, are reported in test results from the Node 1 and airlock elements. Test results from the Node 2 element reported hexamethylcyclotrisiloxane in addition to trimethylsilanol.

\section{Russian On-orbit Segment Elements}

Offgassing tests conducted on ROS elements tend to report greater contributions from the alcohol, aldehyde, aromatic, ketone, and hydrocarbon class as summarized by Table 6 . The offgassing rate from the $\mathrm{SM}$ is significantly higher due to contributions in the alcohol, ester, and ketone classes. Ethyl acetate is the predominant ester. The offgassing rate for the ketone class is dominated by 2-butanone.

Fig. 3 summarizes the percentage contribution of each functional class to the average ROS element offgassing rate that excludes SM ethyl acetate contribution. As with the cargo elements and USOS elements, the alcohol and ketone functional classes account for major contributions. Ethanol and nbutanol account for most of the alcohol contribution. A significant difference is noted in the much less significant contribution of the organosilicone class and the much greater contributions of the aromatic and hydrocarbon classes.

It is noted that during ROS element offgassing tests a sampling technique that employs an adsorbent trap is used while the method used the cargo and USOS elements employs evacuated canisters. Although these sampling methods have been shown to be complementary, the adsorbent trapping technique and subsequent analytical method typically reports higher concentrations of hydrocarbon and aromatic compounds lower organosilicone concentrations.

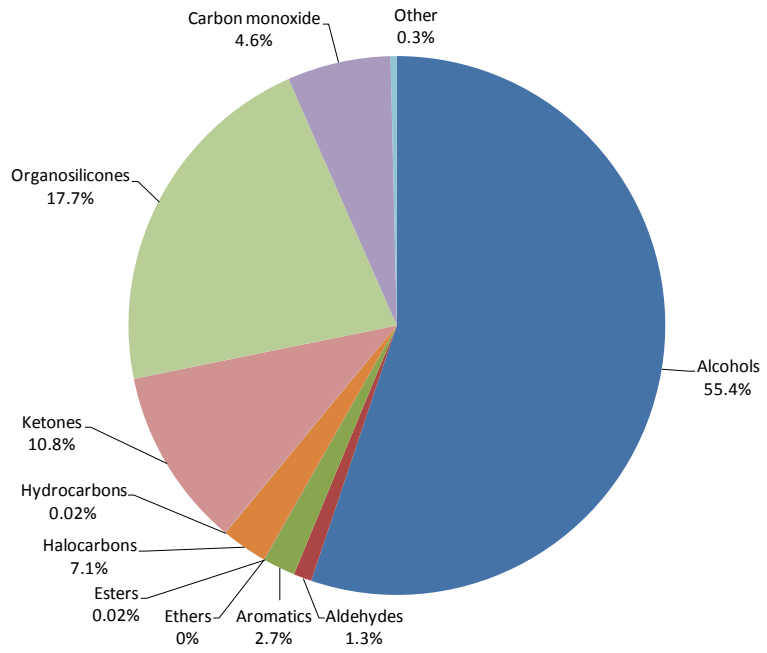

Figure 2. Functional group contributions to the total average USOS element offgassing rate.

\begin{tabular}{|l|r|r|r|}
\hline \multirow{2}{*}{\begin{tabular}{c}
\multirow{2}{*}{$\begin{array}{c}\text { CHEMICAL } \\
\text { CLASS }\end{array}$} \\
\cline { 2 - 4 }
\end{tabular}} & \multicolumn{3}{|c|}{$\begin{array}{c}\text { OFGASSING RATE } \\
\text { (mg/hour) }\end{array}$} \\
\cline { 2 - 5 } & \multicolumn{1}{c|}{ FGB } & \multicolumn{1}{c|}{ SM } & MRM-2 \\
\hline Alcohols & 0.083 & 3.554 & 0.077 \\
\hline Aldehydes & 0.164 & 0.006 & 0.013 \\
\hline Aromatics & 0.606 & 0.068 & 0.164 \\
\hline Esters & 0 & 4.375 & 0.061 \\
\hline Ethers & 0 & 0 & 0.005 \\
\hline Halocarbons & 0.019 & 0.016 & 0 \\
\hline Hydrocarbons & 0.508 & 0.052 & 0.178 \\
\hline Ketones & 0.105 & 1.058 & 0.045 \\
\hline Organosilicones & 0 & 0 & 0 \\
\hline Carbon monoxide & 0 & 0 & 0.138 \\
\hline Other & 0 & 0 & 0.004 \\
\hline \multicolumn{1}{|c|}{ TOTAL } & $\mathbf{1 . 4 8 5}$ & $\mathbf{9 . 1 2 9}$ & $\mathbf{0 . 6 8 5}$ \\
\hline Table & &
\end{tabular}

Table 6. Functional class contribution to ROS element offgassing.

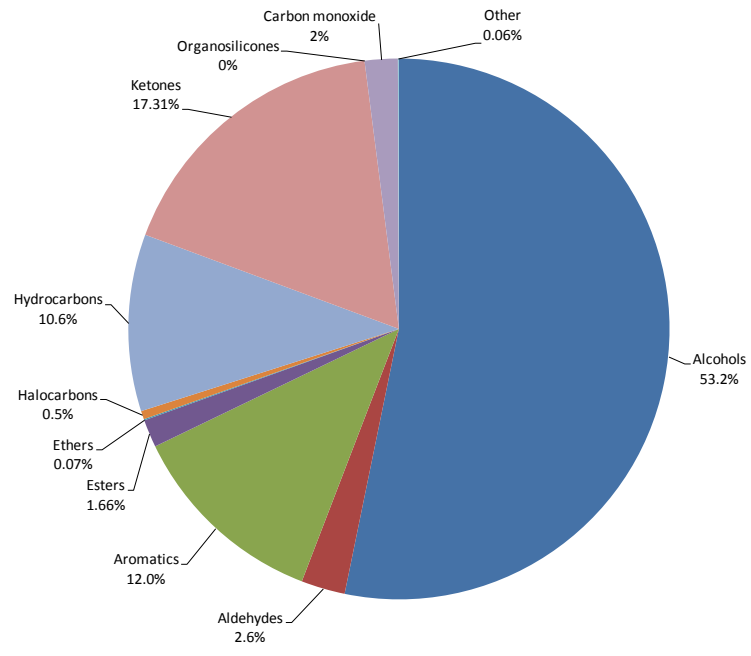

Figure 3. Functional group contributions to the total average ROS element offgassing rate. 


\section{Comparison to ISS Cabin Atmosphere Sample Analysis Results}

At steady state the cabin trace contaminant concentration equals the ratio of generation rate to removal rate. Assuming that the combined element offgassing load has achieved a reasonably steady state the cabin concentration can be expected to reflect the functional class composition of the equipment offgassing load. Fig. 4a shows the composite offgassing rate composition for all documented element offgassing tests. The composite element offgassing rate consists primarily of $47.5 \%$ alcohols, $15 \%$ ketones, and $15.8 \%$ organosilicones. Aldehydes (2\%), aromatics (5.4\%), halocarbons (4.3\%), hydrocarbons (4.5\%), and carbon monoxide (4\%) contribute to a lesser extent. Fig. 4b shows the average functional group contribution to the total average cabin concentration reported by 275 U.S. samples and 174 Russian samples collected from the ISS cabin between December 2000 and September 2009.

The cabin concentration's functional group composition shown by Fig. $4 \mathrm{~b}$ compares well with that of the composite element offgassing rate with the exception of the halocarbon and hydrocarbon classes. Over time the halocarbon concentration in the ISS cabin has been shown to have decreased over time as the overall cabin converges toward a steady state. ${ }^{9}$ The aliphatic hydrocarbon contribution to the cabin trace contaminant concentration is significantly higher than the composite element offgassing rate might indicate. Two considerations relating to sample analytical methods and offgassing test duration may explain this difference. First, the aliphatic hydrocarbons are reported almost exclusively from samples collected using Russian sorbent trapping and gas analysis techniques. Second, given the very few samples collected and analyzed by this method combined with the relatively short duration for the Russian element offgassing tests, it is likely that the testing duration was insufficient for aliphatic hydrocarbon compounds to offgass to a significant extent.

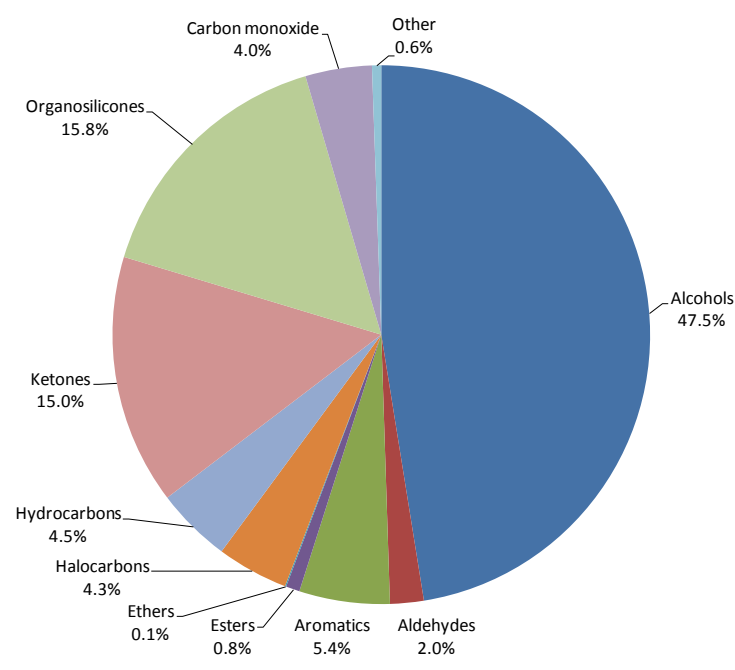

a)

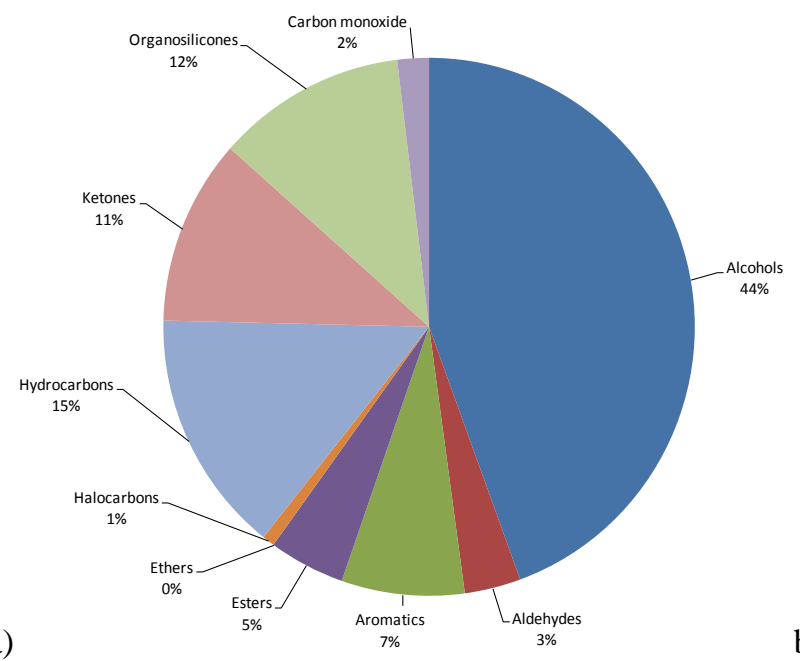

b)

Figure 4. Functional group representation. a)Composite element offgassing test results b)In-flight air quality sample concentration.

\section{Offgassing Rate Growth from Cargo Transfers}

Cargo delivered to the ISS contributes to offgassing rate growth over time. Evaluation of the equipment offgassing load at $I S S$ assembly stage 5A consisting of the USL, Node 1, FGB, and SM shows a $21.6 \mathrm{mg} / \mathrm{hour}$ rate. Between February 2001 and February 2010, a total of 9 MPLM logistics flights, 20 Soyuz missions, 33 Progress logistics flights, and 10 other cargo transfers to the ISS have been accomplished. The net offgassing contribution for each mission type compared to the $21.6 \mathrm{mg} /$ hour rate at assembly stage 5A varies. MPLM missions average a net increase of $19.1 \%$ while the Progress vehicle contributes average net increases of $3.7 \%$. Very little equipment transfer occurs via the Soyuz vehicle which averages a net offgassing contribution increase per flight of $0.52 \%$. Other cargo transfer events contribute approximately $4.2 \%$ each. In total, evaluation of net equipment transfer indicates a $345 \%$ offgassing rate growth, or $74.6 \mathrm{mg} /$ hour, compared to assembly stage $5 \mathrm{~A}$.

\section{Element Offgassing Test Results as a Predictive Basis}

Data acquired from element offgassing tests may be useful as a predictive basis for the overall vehicle offgassing load. The total raw offgassing rates summarized by Table 2 and 3 indicate habitable elements contribute approximately $29.4 \mathrm{mg} /$ hour to the total offgassing load. This base equipment offgassing rate when combined with the predicted $74.6 \mathrm{mg} /$ hour offgassing load growth from cargo and a 6-crewmember contribution of $16.1 \mathrm{mg} /$ hour from the 
ISS TCCS design specification load yields a $120.1 \mathrm{mg} / \mathrm{hour}$ total trace chemical generation rate. This rate, when acted on by active contamination control equipment, predicts approximately $2.9 \mathrm{mg} / \mathrm{m}^{3}$ total non-methane trace contaminant concentration in the cabin.

A second predictive technique uses a generalized equipment offgassing rate and metabolic rate basis documented by Reference 3 . This predictive approach requires estimating the total equipment mass in the spacecraft cabin. As a general rule, the equipment distribution is estimated to be $150 \mathrm{~kg} / \mathrm{m}^{3}$ of free volume based on analysis of equipment mass density for six Spacelab mission modules. The ISS total free volume is approximately $762 \mathrm{~m}^{3}$ as of assembly stage $20 \mathrm{~A}$ providing an equipment mass basis of $114,300 \mathrm{~kg}$. Close examination of the ISS element offgassing test results finds that thirty-seven compounds are reported by three or more testing results. Applying the generalized trace contaminant load model from Reference 3 for equipment offgassing and six people to the thirty-seven compounds yields a $216 \mathrm{mg} /$ hour total generation rate. The predicted total non-methane trace contaminant concentration using specific offgassing rate for the habitable element load is approximately $5.3 \mathrm{mg} / \mathrm{m}^{3}$.

Analysis results for samples collected from the ISS cabin between late July and early September 2009, the most recent sample set returned from the $I S S$, average $4.4 \mathrm{mg} / \mathrm{m}^{3}$ for the total non-methane trace contaminant concentration. In comparison, the predicted $2.9 \mathrm{mg} / \mathrm{m}^{3}$ concentration using offgassing test data as the basis is approximately $34 \%$ lower. In comparison the prediction using the generalized trace contaminant load model is $20 \%$ higher. In both cases the concentration for the alcohol class is underestimated. The total alcohol concentration reported from flight sample analyses averages $2.96 \mathrm{mg} / \mathrm{m}^{3}$ compared to $1.33 \mathrm{mg} / \mathrm{m}^{3}$ predicted from the rate derived from offgassing tests and $2.06 \mathrm{mg} / \mathrm{m}^{3}$ predicted from the generalized trace contaminant load model. The predicted $1.44 \mathrm{mg} / \mathrm{m}^{3}$ for all other chemical compound classes obtained from the offgassing test data basis agrees better with the average 1.41 $\mathrm{mg} / \mathrm{m}^{3}$ reported by flight samples. The generalized trace contaminant load model predicts $2.81 \mathrm{mg} / \mathrm{m}^{3}$ for the nonalcohol compound classes, an over-prediction of nearly $100 \%$. The implication is that there are likely alcohol sources on board the ISS that are not accounted for by the offgassing tests and that equipment aging is not fully accounted for by the generalized offgassing load model for the non-alcohol chemical classes. Alcohol sources that are not easily accounted for, and which can be difficult to quantify, may include crew preference items, housekeeping operations, payload chemicals and operations, and spacecraft system vents into the cabin. Comparatively, using the generalized equipment offgassing load model basis provides the more conservative estimate.

\section{Conclusion}

Subjecting completely assembled crewed spacecraft and cargo elements to offgassing tests serves an important role in the overall effort to maintain an acceptable cabin environment. The most prevalent chemical compound classes observed during ISS element offgassing tests include alcohols, ketones, and organosilicones. Chemical compounds in the aldehyde, aromatic, and halocarbon functional classes are observed to a lesser extent. Carbon monoxide is observed occasionally. Offgassing rates derived from spacecraft offgassing tests or a generalized load model provide a good basis, when combined with the trace contaminant loads from human metabolism and net cargo transfers as necessary, provide a good estimate for the total spacecraft offgassing rate. Accounting for chemical emissions from crew preference items, housekeeping procedures, payload operations, and spacecraft system operations may provide a more accurate total vehicle trace contaminant generation rate estimate.

\section{References}

${ }^{1}$ Perry, J. L., "Elements of Spacecraft Cabin Air Quality Control,”NASA TP-1998-207978, 1998, pp. 3-5.

${ }^{2}$ Perry, J. L., "Trace Contaminant Control," Safety Design for Space Systems, edited by G. E. Musgrave, A. M. Larsen, and T. Sgobba, Elsevier, Oxford, UK, 2009, pp. 298-211.

${ }^{3}$ Perry, J. L., "Trace Chemical Contaminant Generation Rates for Spacecraft Contamination Control System Design," NASA TM-108497, 1995.

${ }^{4}$ Perry, J. L., "Predictive Techniques for Spacecraft Cabin Air Quality Control," $31^{\text {st }}$ International Conference on Environmental Systems, 2001-01-2398, SAE, Orlando, FL, 2001.

${ }^{5}$ Perry, J. L., James, J. T., Cole, H. E., Limero, Beck, S. W., "Rationale and Methods for Archival Sampling and Analysis of Atmospheric Trace Chemical Contaminants On Board Mir and Recommendations for the International Space Station," NASA TM-108534, 1997.

${ }^{6}$ Crivello, M. and Rampini, R., “FM1 Total Offgassing Test Report,” Alenia Aerospazio MLM-RP-AI-0435, 1998.

${ }^{7}$ Crivello, M. and Rampini, R., "FM2 Total Offgassing Test Report," Alenia Aerospazio MLM-RP-AI-0500, 1999.

${ }^{8}$ Olcott, T. M., "Development of a Sorber Trace Contaminant Control System Including Pre- and Post-Sorbers for a Catalytic Oxidizer," NASA CR-2027, 1972, pp. 9-10.

${ }^{9}$ Aguilera, T. and Perry, J. L., "Root Cause Assessment of Pressure Drop Rise of a Packed Bed of Lithium Hydroxide in the International Space Station Trace Contaminant Control System," $39^{\text {th }}$ International Conference on Environmental Systems, 200901-2433, SAE, Savannah, GA 2009, p. 4. 